\title{
صياغة أسئلة البحث للبحوث العلمية في تعليم اللغة العربية
}

\author{
"عارف الرحمن حكيم
}

\section{Email: arif@iain-antasari.ac.id}

\section{Abstract}

Research problem is the first thing to be found by researcher. Then, he should limit it clearly so that it can be easy to be understood. At this step, the researcher needs special formula to write the problems statement in the form of research questions which the answers of them are the research goals. Writing good research question formulation will provide convenience for researchers in conducting research process. Thus, it is essential to give appropriate criteria in formulating research questions. This article describes some criteria for writing the formulation of research questions along with examples.

$$
\text { الكلمة الرئيسية: البحث العلمي، مشكلة البحث، أسئلة البحث }
$$

عرفنا أن البحث يبدأ من وجود المشكلة. و هي موقف غامض يثير قلق الباحث و يولد لديه رغبة في الكشف عن هذا الغموض. فإن الأنسان في تفاعله مع بيئنه - و كذلك المدرس و المحاضر في بيئهما التربوية - يواجه العديد من المشكلات و المواقف. لكن، لم تكن هذه المشكلات و المواقف كلها تستحق أن تكون موضوعا للدراسة و البحث العلمي. هناك عدد من المعايير التي تساعد الباحث في اختيار مسكلاته. يتعلق بعض هذه المعايير بالباحث نفسه من حيث قدرته و رغبته على القيام بهذا العمل. و يتعلق بعضها بعوامل اجتماعية خحارجية مثل فائدة هذه المشكلة بالنسبة للمجتمع. و بعد أن يصل الباحث في اختيار سليم لمشكلة البحث يبدأ في مهمة جديدة يمكن القول أها أصعب مراحل البحث العلمي و هي مرحلة تحيديد المشكلة. و تسمى أيض هذه المرحلة كتابة مشكلة البحث أو أسئلة البحث. فما المقصود بتحديد المشكلة؟ و كيف العمل عليه؟ إننا نعنى بتحديد المشكلة هو صياغة المشكلة في عبارات واضحة و مفهومة و محددة تعبر عن مضمون المشكلة و بجالها، و تفصلها عن سائر المحالات الأخرى. 


\section{ب- تعريف البحث العلمي}

البحث العلمي هو نشاط إنسائ يتسم بإتباع قواعد واضحة ومنظمة ويهدف إلى حل

مشكلة أو استقصاء عن وضع معين أو تصحيح فرضية أو التحقق من صحة نتائج توصلت إليها دراسة سابقة، والاستفادة من الدراسات السابقة، على اعتبار أن المعرفة متراكمة، وأن يبدأ من

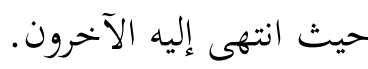

يتكون مصطلح البحث العلمي من مقطعين الأول "البحث" وهو كلمة مشتقة من مصدر الفعل الماضي بحث ومعناه: حاول، تتبع، بحث،سعى، تحرى ...الخ، والمقطع الثاني "العلمي" وهو كلمة مشتقة من كلمة العلم ومعناه: الحقيقة، المعرفة، التجريب ... الخ. الاختلاف واسع الانتشار في استخدام الكلمة "بحث" يوحي بتعدد التفسيرات الممكنة، ينحصر إحداها في أولئك الذين يعتقدون أهم يستخدمون الكلمة بمعنى صحيح و حصرى و هم أقلية محدودة، و على كل حال فإن تحليل جميع التعاريف و الاستخدامات السارية فيما يتعلق بكلمة "بحث"، أمر يتجاوزه الحيز المتاح، و من خلال استعراضنا لتعاريف متعددة لكلمة "بحث" نستطيع أن نميز بعض الجيوط أو العناصر العامة.

إن الفعل research يفيد البحث، يعنى ينشد ثانية، أو يفحص الشيء ثانية بعناية، أم الاسم "بحثُ " فيعرف عادة بأنه التقصى بعناية. و بخاصة الاستقصاء المنهجي في سبيل زيادة بحموع ئى المعرفة، الذي يزداد بإضافة معرفة جديدة.

البحث في اللغة هو التفحص و التفتيش. و أما اصطلاحا هو إثبات النسبة إيجابية أو سلبية بين الشيئين بطريق الاستدلال. و أيض هو بمعنى طلب الحقيقة و تقصيها و إشاعتها بين

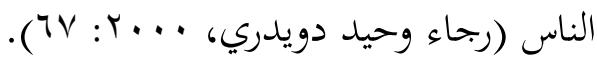
عليه يمكن تعريف البحث العلمي كما يلي:عمل فكري منظم يقوم به شخص مدرب وهو

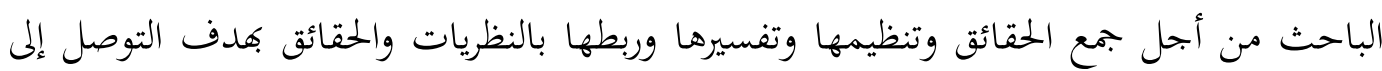
حل مشكلة أو للإضافة إلى المعرفة في حقل من حقول المعرفة. و قيل أيضا أنه نتاج إجراءات منظمة و مصممة بدقة من أجل الحصول على أنواع المعرفة و التعامل معها بموضوعية و شمولية، و تطويرها بما يتناسب مع مضمون و ابتحاه المستجدات البيئية الحالية و المستقبلية (رجاء وحيد

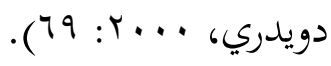


و قد يوجد تعاريف كثيرة للبحث العلمي ومنها : هو بجهود منظم ومسلسل بطريقة

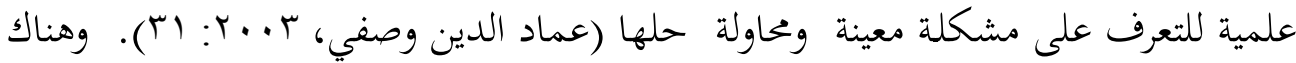
تعريف ( Whitney ) : البحث العلمي هو استقصاء دقيق يهدف إلى اكتشاف حقائق وقواعد

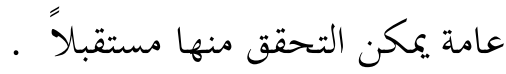

كما يعرف ( Hillway ) البحث : بأنه وسيلة للدراسة يمكن بواسطتها الوصول إلى حل لمشكلة محددة , وذلك عن طريق التقصي الشامل والدقيق لجميع الشواهد والأدلة التي يمكن التحقق منها والتي تتصل بهذه المشكلة .

ويعرف ماكميلان وشوماخر البحث بأنه عملية منظمة لجمع البيانات أو المعلومات وتحليلها لغرض معين ـ أما توكمان فيعرفه بأنه محاولة منظمة للوصول إلى إجابات أو حلول للأسئلة أو المشكلات التي تواجه الأفراد أو الجماعات في مواقفهم ومناحي حياقم (ربكي مصطفى عليان، (IV: r...r

ويمكن أن نستنتج من خلال التعاريف السابقة أهم النقاط التي يرتكز عليها البحث

العلمي :

( ) المشكلة حيث أن بدون وجودها لا يمكن أن نتحدث عن بحث علمي .

r عملية دقيقة تعتمد على طريقة علمية في معالجة هذه المشكلة .

r) إعتماده على بيانات ومعلومات للوصول إلى نتيجة يمكن التحقق منها مستقبلاً

ع) يمكن للبحث العلمي أن يعالج مشكلات في شتى الميادين .

0) يمكن للبحث العلمي توسيع حقل المعرفة في أي بحال .

وبالتالي فالبحث العلمي يمكن أن يعرف على أنه :بحث واستقصاء علمي منظم يقوم على أساس قاعدة بيانات لبحث مشكلة معينة وذلك بهدف الوصول إلى إجابات وحلول للمشاكل موضوع البحث.

ج- صفات الباحث العلمي و قد عرف رجاء وحيد دويدري (رجاء وحيد دويدري: rآ) الباحث العلمي بأنه هو المخطط و المنظم و المنفذ و الموجه لمختلف مراحل البحث العلمي، وصولا إلى النتائج العلمية و المنطقية، و بهدف الوقوف على دوره في البحث العلمي نتناول جانبين هامين: 
ا. الإعداد: و يشمل التدريب الفكري و الفني و اكتساب خبرة العمل، فعلى الباحث

المتدرب أن يدرس عددا من العلوم المحددة كي يتمكن من العمل على النحو المناسب كباحث علمي، و لا يمكن أن يعتبر تدريبه مكتملا حتى يكتسب قدرا من المهارات في عدد من التقنيات، و من أمثلة ذلك التعبير عن الأشياء بلغة الرموز، و القدرة على معالجة العلاقات القائمة فيما بينها، و صياغة و معالجة الأفكار بلغة صورية، و تقويم مدى صحة هذه العمليات، و معالجة البيانات و فهم مدلولها، و تعميم التجارب في صورة تفضي إلى نتائج هامة متميزة، ثم عرض الأعمال التي اضطلع بها الآخرون في الماضي و العمل الذي يضطلع به الباحث نفسه في الحاضر، كجزء من عملية تتحقق على مراحل، و ترمي إلى إثراء و تنمية مستقبل المعرفة و تطبيقاها، و أن يكون الباحث العلمي قادرا على التعبير عن نفسه بطلاقة و بشكل جذاب، بوساطة الكتابة في المقام الأول، و يضاف إلى ذلك أن المعرفة الجحديدة لا يمكن أن توجد على نهو مقالي ما لم تصبح بوساطة النشر جزءا من الذخيرة المعرفية المشتركة و المتاحة للجميع.

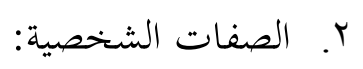

أ- - الخيال و الأصالة: عنصران لا غنى عنهما للإبداع و إن كان هناك عدد مثير للدهشة من العلماء الذين لا يعتقدون أن للأصالة أهمية في البحث، و قد حدد مداوار باييجاز وظيفة الأصالة و الخيال و الإبداع في العملية العلمية كما يلى: كل اكتشاف و كل توسع في الفهم يبدأ كتصور خيالي قلبي، لما قد تكون عليه الحقيقة، ينشأ كتخمين مهم يصدر من داخل النفس. ب- - المثابرة، كما فعله كثير من العلماء المسلمين المتقدين. ت- - حب العلم: فهو الزاد الأساسي الذي يعين الباحث على التقدم في بحثه و الوصول

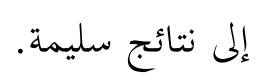
ث- - سعة الأفق: و تشمل قدرة الباحث على الاعتراف بأنه من الممكن أن يكون على خطأ، و قد يؤدي الافتقار إلى هذه القدرة إلى الغرور أو الرضى المفرط عن النفس. نقد الفكرة أو العمل، سواء كان له أو لغيره. 
ح- من التواضع ما يمول دون المبالغة في التقدير ما يسلم به مقدما من فروض ذات طابع شخصي، كما يتطلب القدرة على طرحها جانبا حتى يمكن اتباع الفروض

$$
\text { التي يسلم بها باحثون آخرون. }
$$

خ- الحصافة، و التحلي بصفات متضادة، فعلى الباحث العلمي أن يعبر عن فرديته، و لكن عليه أيضا أن يفعل ذلك في إطار الأوضاع الاجتماعية السائدة.

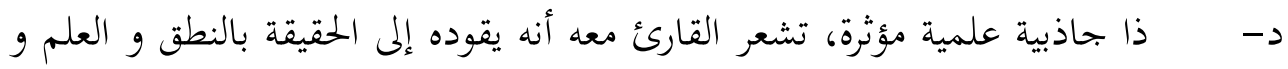

$$
\text { التأثير، و أنه إن جادل بالحق. }
$$

و قال ذوقان عبيدات أنه ينبغي أن تتوفر في الباحث صفات معينة منها (ذوقان عبيدات

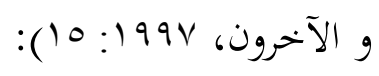

1- أن يحرص على البحث عن المسببات الحقيقية للأحداث والظواهر، على اعتبار أن لكل

$$
\text { حدث سببًا، ويعني ذلك أن لا يكتفي بالمبررات السطحية. }
$$

r- - أن يتسم عمله بالدقة في جمع الأدلة الموصلة إلى الأحكام ويعني ذلك اعتماده على مصادر موثقة.

$$
\begin{aligned}
& \text { r- أن لا يتسرع في إصدار أحكام دون توفر أدلة صحيحة وكافية. } \\
& \text { ع- - أن يكون متحررًا من الجمود والتحيز. }
\end{aligned}
$$

0ـ أن يكون لديه القدرة على الإصغاء للآخرين وتقبل نقدهم وآرائهم حتى لو تعارضت مع

7- أن يكون مستعدًا لتغيير رأيه إذا ثبت أنه أخطأ.

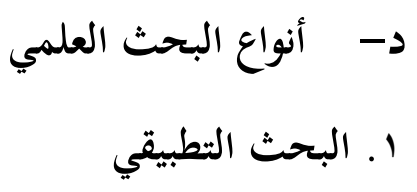

يهدف هذا النوع من البحوث إلى معالمة المشكلات القائمة لدى المؤسسات الاجتماعية والاقتصادية حيث يقوم الباحثون المعنيون بتحديد واضح للمشكلات التي تعاني منها تلك

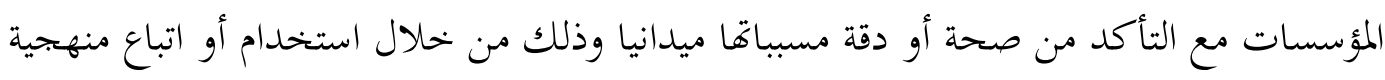


علمية ذاتت خطوات بحثية متدرجة وصولا لمحموعة من الأسباب الفعلية التي أدت إلى حدوث هذه المشلات أو الظواهر مع اقتراح بحموعة من التوصيات العلمية التي يمكن أن تسهم في التخفيف من حدة هذه المشكلات أو معالجتها فهائيا.

\section{r. (البحث النظري (الأساسي)}

إن الهدف الأساسي من هذه البحوث هو تطوير مضمون المعارف الأساسية المتاحة في مختلف حقول العلم والمعرفة الإنسانية أي يهدف إلى إضافات معرفية وعلمية لدعم حياة المحتمعات الإنسانية وذلك من خلال وضع تصورات للبناءات النظرية للظواهر الاجتماعية والانسانية ذات العلاقة المباشرة بالنماذج المثالية أو ما يجب أن تكون عليه المفاهيم من حيث اعتمادها على معاييير أو مقاييس قابلة للقياس

\section{هـ - - أنواع مناهج البحث}

تعددت وجهات النظر في تصنيف مناهج البحث فقد وصف لممان و مهرنز $19 \vee 9$

تصنيف مناهج البحث في العلوم السلوكية بأنه تصنيف اعتباطي أي ليس مبنيا على أسس متفق عليها يعتمدها جميع علماء المنهجية و هذا ما أدى إلى أن كل واحد منهم يصنفها تصنيفا فرديا يعتمد فيه على تحليله الذاتي وخبراته العلمية.

فقد شبه تصنيف مناهج البحث بتصنيف الكتب في المكتبة فهي تصنف تبعا للوها او موضوعها او عنوافا مشيرا بذلك إلى عدم اعتماد تصنيف موحد بين علماء المنهجية و مؤكدا أهمية عدد من العوامل في تأثيرها بعملية التصنيف ومن هذه العوامل ما يلي : - - إنه ليس هناك اتفاق مسبق على مصطلح واحد تدعى به مناهج البحث فهناك من يوردها تحت مصطلح مناهج و هناك من يوردها تحت مصطلح تقنيات أو إجراءات أو تصميمات و و الذي يوردها تحت مصطلح مناهج مثلا يرى إن مصطلح الأنواع له مدلول آخر غير المناهج والذي يوردها تحت مصطلح طرق يرى أيضا إن مصطلح الإجراءات له مدلول أخر يختلف عن مصطلح الطرق. تحلل المعلومات بأكثر من طريقة فمثلا عند إجراء بحث تاريخي قد يظن لأول وهلة انه لا يمكن معه تطبيق منهج أخر و لكن ذلك في الحقيقة ممكن فمثلا قد يكون الموضوع تاريخي ذو صلة بعدد من الأفراد أو المؤسسات مما يجعل من المتعذر على الباحث تطبيقه و دراسته على كل 
الأفراد مما يضطره إلى اختيار عينة و اختيار العينة يعد أسلوبا من الأساليب التي تطبق كثيرا في

$$
\text { المنهجين الوصفي و التجريبي. }
$$

- تعقد الظاهرة الإنسانية و تداخل العوامل المؤثرة فيها الماضي منها و الحاضر و المستقبل و ما لهذا من تاثير على عملية التصنيف فالموضوع التاريخي مثلا له امتداده الحاضر و الحاضر له جذوره التاريخية. - التداخل الكبير في مفهوم كل من المصطلحات التالية منهج البحث، اداة البحث و طريقة تحليل المعلومات. إن تطبيق المناهج العلمية للبحث يهدف باستمرار إلى توسيع الآفاق المعرفة العلمية حول مختلف بحالات الاهتمام من قبل الباحثين في العالم و من وقت لآخر و ذلك بسبب تطور الحياة الإنسانية لبني البشر في النواحي الاقتصادية و الاجتماعية و السياسية و التكنولوجيا وغيرها. و انطالاقا مما تقدم التصنيف المتبع في هذا البحث هو طبقا لما يلي : ( ) البعد الزماني : حيث تصنف مناهج البحث فيه إلى : - المنهج التاريخي : الذي يطبق لدراسة ظاهرة حدثت في الماضي. - المنهج الوصفي : الذي يطبق لدراسة ظاهرة معاصرة. - المنهج التجريبي : الذي يطبق بغرض التوقع المستقبلي للظاهرة المدروسة.

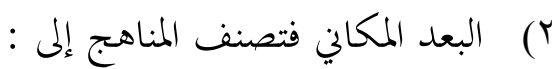
- البحث الوثائقي : الذي يجري بالمكتبة بصورة كيفية. - البحث الحقلي (دراسة الحالة ) : الذي يجري من خلال المعايشة الفعلية. - البحث المسحي : الذي يجري في الميدان. - تحليل المحتوى : الذي يجري بالمكتبة بصورة كمية.

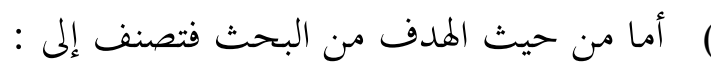
- البحث الارتباطي: الذي يهدف لتوضيح العلاقة بين متغيرين أو أكثر و مقدارها. - البحث السببي المقارن: الذي يهدف لاستنتاج الأسباب الكامنة وراء سلوك معين. - البحث التطوري : الذي يهدف لمعرفة اثر الزمن على استجابة العينة للموقف المطروح. 


\section{و - مفهوم مشكلة البحث}

المشكلة بوجه عام هي سؤال مطروح يتطلب حلا، و بوجه خاص هي مسألة عملية أن نظرية لا يوجد لما مباشرة حل مطابق. و يقول الجرجاني في التعريفات: المشكل ما لا ينال المراد منه إلا بتأمل بعد الطلب. و من هنا ينبغي أن يطرح الباحث في بحثه سؤالا كبيرا يحتاج إلى إجابة أو حل، و هذا الحل لم يقدمه بشكل مباشر حتى الآن باحث آخر. و يبين الباحث معالم المشكلة، و حدودها، و الأسباب التي أدت إليها، و طبيعة الظروف التي نشأت فيها، و تطورها التاريخي إن كان لها مثل هذا البعد. و إذا كانت المشكلة مركبة، يقوم الباحث بتحليلها وردها إلى عدة مشكلات بسيطة، تمثل كل مشكلة منها مشكلة فرعية يساهم حلها في حل جزء من المشكلة الرئيسية (محمد عثمان الخشت، .999 19: 19 ).

و قد عرف د. رجاء وحيد المشكلة في البحث العلمي بأها جملة سؤالية تسأل عن العلاقة

القائمة بين متحولين أو أكثر، و جواب هذا السؤال هو الغرض من البحث العلمي،و ليس من

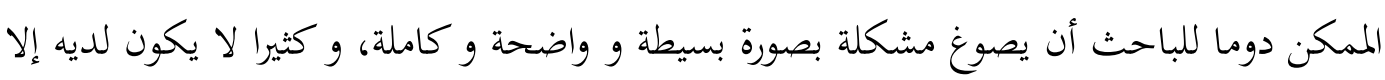
فكرة غامضةو مشوشة و عامة عن المشكلة،و هذا من طبيعة تعقد المشكلات العلمية، و تعقد طرائق البحث فيها، و قد يقضي الباحث فترة طويلة من الزمان في البحث و التمحيض و التفكير قبل أن يحدد المشكلة ويصوغ الأسئلة التي يجب أن يطرحها، و يبحث عن أجوبة، و مع ذلك فإن صياغة المشكلة صياغة صحيحة و دقيقة جزء من أهم أجزاء البحث العلمي، و خطوة أساسية من خطواته، و رغم صعوبته إلا أنه أمر ضروري و لازم (رجاء وحيد دويدي، المرجع السابق، ص. $\cdot(1 \cdot v$

فتكون مشكلة البحث هي الموضوع الذي يختاره الباحث لإجراء البحث، ويمثل اختيارها أحد أهم المراحل وأكثرها صعوبة ويستغرق في العادة الكثير من الوقت والجها. ويترتب على اختيارها

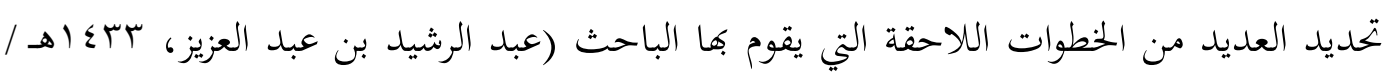
( $r$ T $Y \cdot T$

ز- مصادر المشكلات و معايير اختيارها إن كثيرا من الباحثين المبتدئين يشعرون أن اختيار المشكلة المناسبة للبحث أمرا صعبا يأخذ وقتا طويلا لتعيينه لأن ليست كل مشكلة ظهرت في حياتنا صحيحة لعملية البحث العلمي. فإنمم يحتاجون إلى المصادر التي تساعدهم في اختيار المشكلة هي المصادر التالية: 
ا. القراءة، وذلك من خلال قراءة الكتب و المقالات ذات الصلة بموضوع اهتماماتنا. فتبرز لدينا الأسئلة و تلوح في أذهاننا، مما يحملنا على دراستها و الحصول على إجابةها.

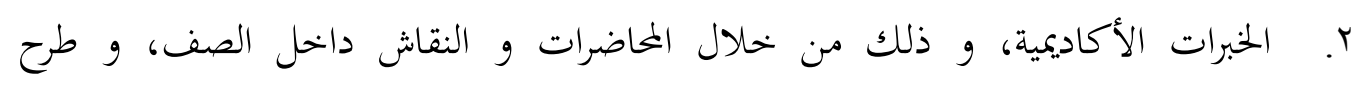

$$
\text { المشكلات الواجب دراستها. }
$$

r. الخبرات اليومية، فنحن نكتسب خبرات جديدة يوميا. فالحياة ديناميكية. لذا فهناك أسئلة

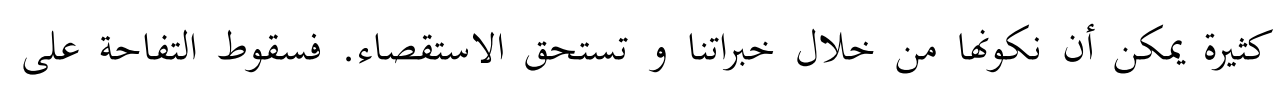
الأرض هو الذي جعل نيوتن يكتشف قانون الجاذبية.

ع. التعرض للمواقف الميدانية، كالزيارات الميدانية و التدريب تبعل الفرد يواجه مشكلات

تستدعي حلولا معينة.

•. الاستشارات، و ذلك من خلال البحث مع الأخصائين و الباحثين و الإداريين و رجال

$$
\text { الأعمال بعض المشكلات التي تستحق أن تبحث و يوضح لما حلول. }
$$

T.

$$
\text { اهتمامات معينة تطور أفكارا جديدة حول مشكلات معينة. }
$$

V. البحث، إذ أن البحث في مشكلة معينة يمكن أن يقترح البحث في مشكلات أخرى.

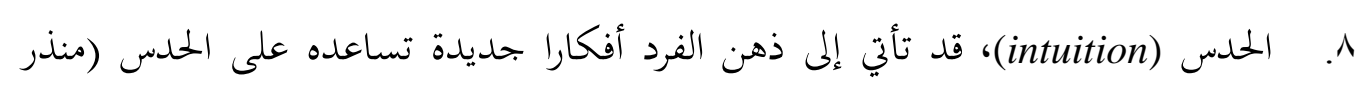

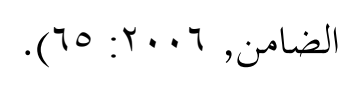

و مع الملاحظة في هذه المصادر، يلزم أيضا للبحث أن يهتم في عمليته بعض معايير اختيار

المشكلة التالية :

1. اهتمامات الباحث، فالمشكلة يفترض أن تثير اهتمام الباحث و أن تشكل تحديا بالنسبة

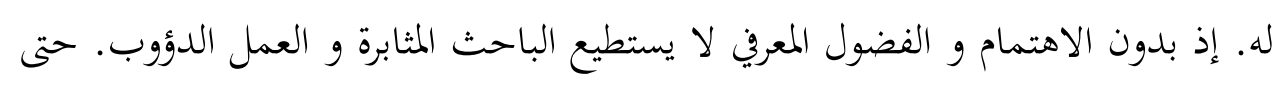

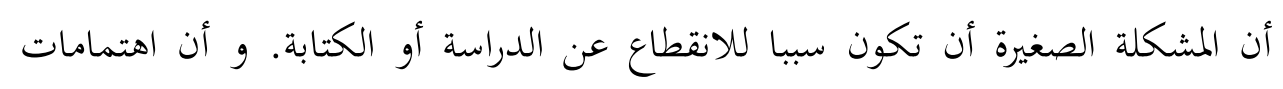
الباحث تعتمد على خلفيته التربوية، و خبرته، و جديته و حساسيته. r. كفاءة الباحث. إن اهتمامات الباحث لوحدها لا تكفي إذ لا بد أن يكون الباحث كفوؤا حتى يستطيع أن يدرس المشكلة التي يريد أن يكتب حولها، وكذلك يجب أن تتوفر لديه المعرفة الكافية في الموضوع و كذلك المنهجية و الطرق الإحصائية المناسبة. r. المصادر الذاتية للباحث. بما في ذلك تكلفة البحث فإن لم يكن لديه التمويل المالي الكافي فإن ذلك سيعيق عمله، إلا إذا حصل على دعم مالي خارجي و بالإضافة إلى التمويل المالي الوقت المتوفر للكتابة. 
ع. أن تكون المشكلة قابلة للبحث . إذ أن كل مشكلة بحثية تتضمن سؤالا أو عدة أسئلة. و

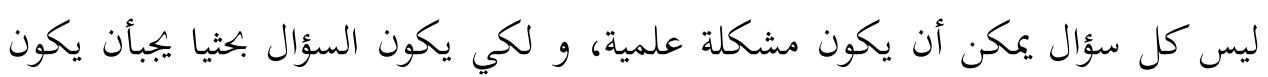

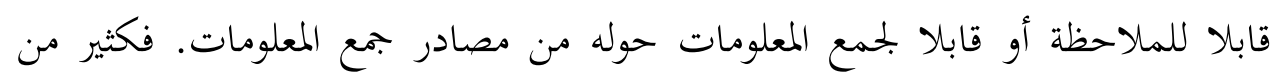

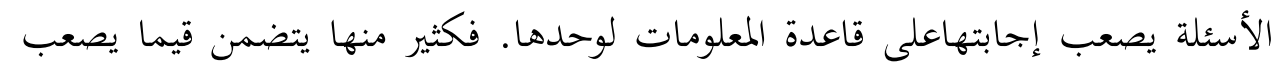
قياسها. ه. أهمية المشكلة البحث. إن البحث يفترض أن يركز على المشكلات ذات الأهمية و الطارئة.

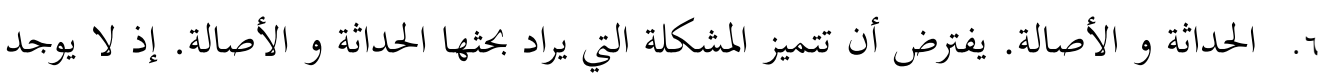

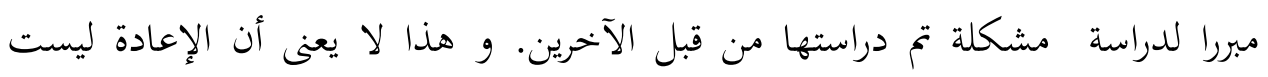

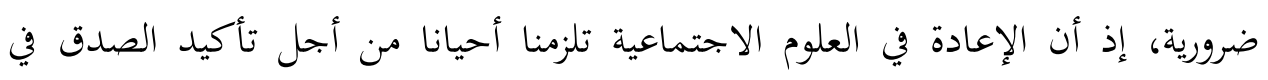
وماقف مختلفة. V. أن يكون البحث عمليا (feasible)، و لكي يتحقق ذلك يجب مراعاة ما يلى:

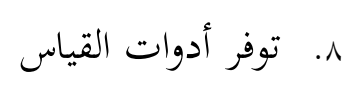

9. . أن تتوفر الرغبة لدى الأشخاص المراد مقابلتهم.

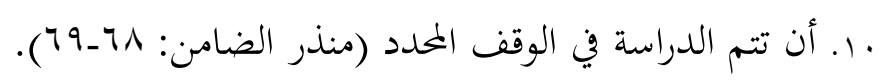

\section{ح- مواصفات المشكلة الجيدة}

هناك مواصفات معينة يتعين توفرها حتى يمكن اعتبار المشكلة جيدة وجديرة بالبحث والدراسة

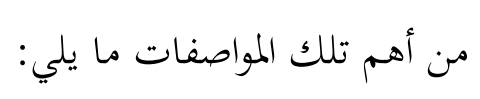

1- أن تستحوذ على اهتمام الباحث وتتناسب مع قدراته وإمكاناته.

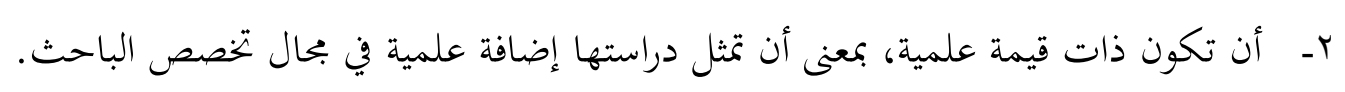

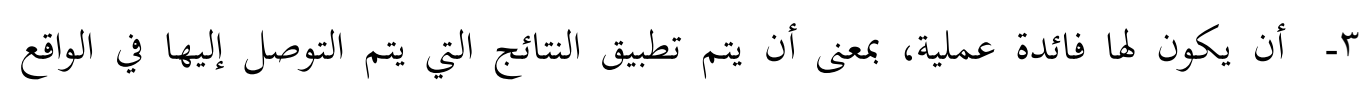

$$
\text { العملي. }
$$

ع- - أن تكون المشكلة سارية المفعول، بمعنى أها قائمة وأثرها مستمر، أو يخشى من عودها

$$
\begin{aligned}
& \text { بحددًا. } \\
& \text { ๑ـ أن تكون جديدة بمعنى أهما غير مكررة أو منقولة. }
\end{aligned}
$$

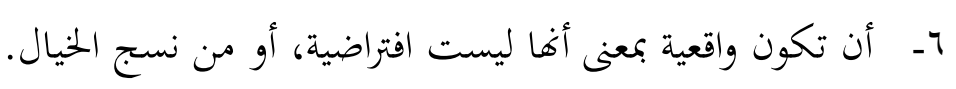


V- أن تمثل موضوعًا محددًا تسهل دراسته، بدلاً من كونه موضوعًا عامًا ومتشعبًا يصعب الإلمام به أو تناوله.

^- - أن تكون المشكلة قابلة للبحث، بمعنى أن تتوافر المعلومات والتسهيلات التي يحتاجها الباحث.

$$
\text { 9- ـ أن تكون في متناول الباحث، أي أن تتفق مع قدراته وإمكاناته. }
$$

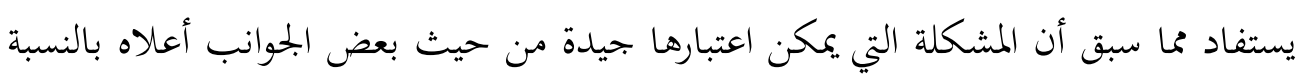

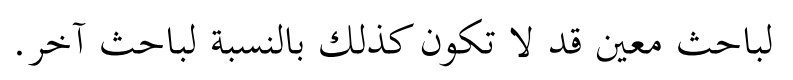

\section{ط- المعايير لصياغة أسئلة البحث الجيدة}

و إن الباحث العلمي قد يقضي فترة طويلة من الزمان في البحث و التمحيض و التفكير قبل

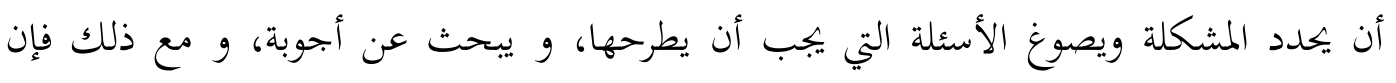

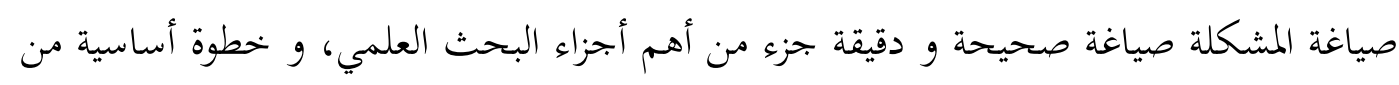

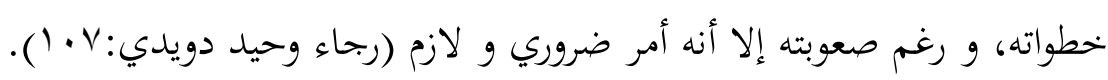

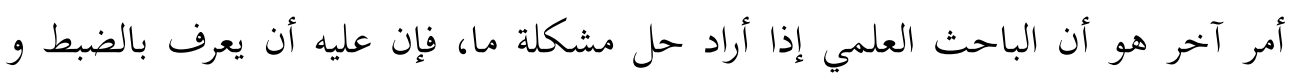

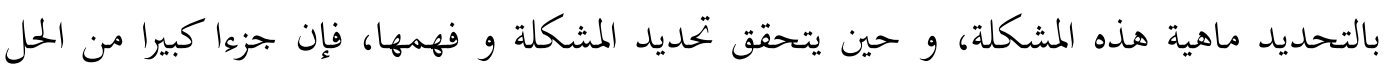

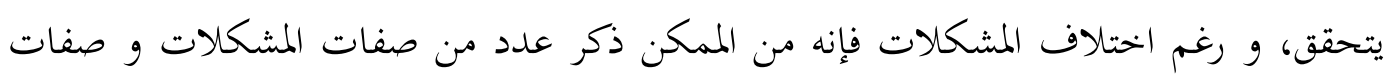

$$
\begin{aligned}
& \text { الصياغة و استعمالها في البحث العلمي الجيد. } \\
& \text { هناك ثمة معايير لصياغة المشكلات الجيدة: }
\end{aligned}
$$

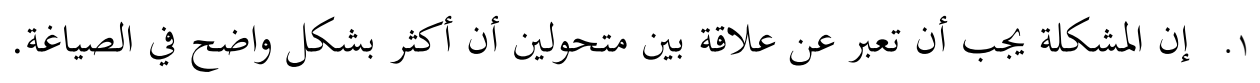

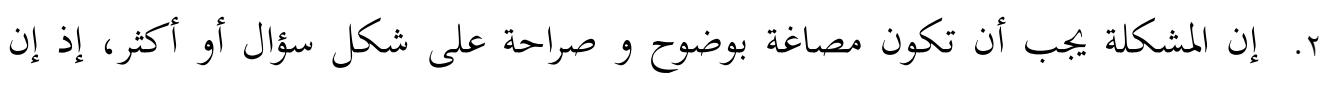

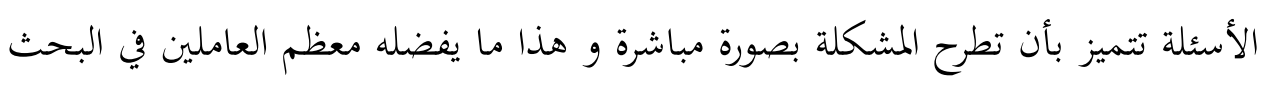

$$
\text { العلمي، و قد تصاغ بعبارة لفظية. }
$$

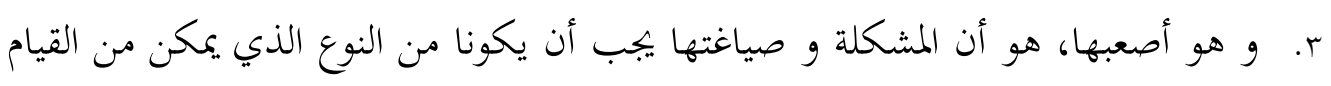

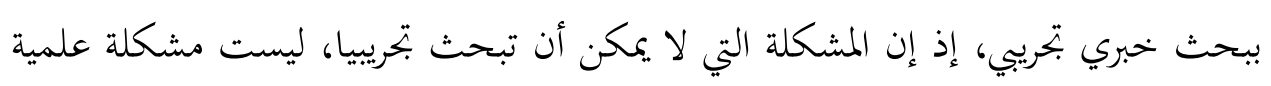

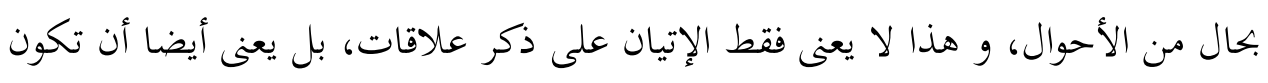


المتحولات من النوع الذي يمكن قياسه، و هناك مشكلة هامة ليست علمية لأن التجريب

$$
\text { ع. عليها صعب أو مستحيل. }
$$$$
\text { ه. أن تسهم بإضافة علمية. }
$$

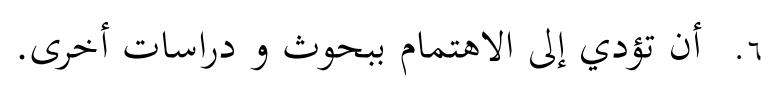

$$
\text { v. أن يستفاد من النتائج بكيث يمكن تعميمها. }
$$

^. أن تقدم فائدة علمية للمجتمع (رجاء وحيد دويدي:9 · (1).

و قد شرح عدنان لطيف بعض المعايير و طريقة مثلي لصياغة تحديد المشكاتات جيدا و

دقيقا و صحيحا. إنه يلزم للباحث أن يقوم صياغة مشكلاته من خلال المعايير التالية ( Adnan

:(Latief, 2002: 20

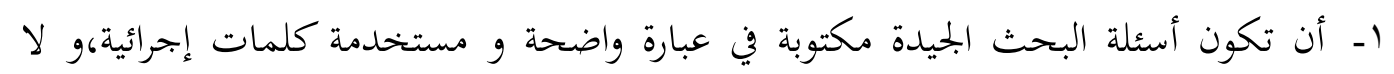

تعطى معنى متشابها، و لا تستخدم مصطلحات تقنية غريبة لم يفهمها القارؤون عامة. المثال: ما علاقة الجنس بإبحاز تعلم اللغة العربية لتلاميذ الصف الثامن بمدرسة مولاورمان

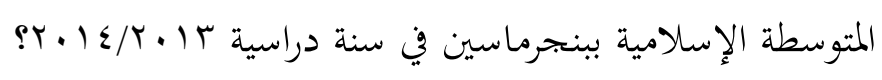
إن هذا سؤال البحث غير واضح لأنه يستخدم كلمة "العلاقة" و هي مصطلح تقني. فالأحسن في كتابة هذا سؤال البحث أن نكتب "هل التلميذات يحصلن على النتيجة أعلى إلى من التلاميذ في تعلم اللغة العربية في الصف الثامن بمدرسة مولاورمان المتوسطة الإسلامية

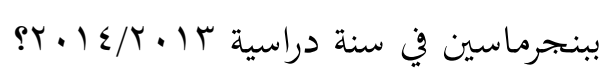

و كذا في المثال الآتي: كيف فعالية استخدام المسرحية في ترقية مهارة الكلام لتلاميذ الصف

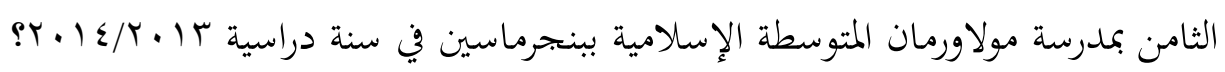
هذا سؤال البحث لم يكن واضحا لأن كلمة "فعالية" مصطلحة تقنية لا نفهمها مباشرة.

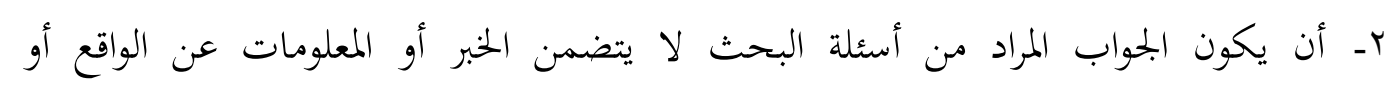
المتغيراتفحسب، بل ينبغي أن يتحمل المعلومات عن العلاقات بين الحقائق و الواقعات أو بين المتغيرات الملاحظة أو المعلومات عن الصيغ و الأنماط و انتظام إجراءات العمل الموجودة في موضوع البحث. المثال: كيف كانت عملية تعليم اللغة العربية في الصف الثامن بمدرسة مولاورمان المتوسطة

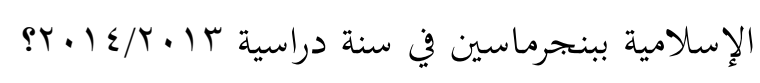


فالجواب المراد من هذا السؤال لا يجاوز الوصف عن عملية التعليم الواقعية التى تتعلق بأحوال

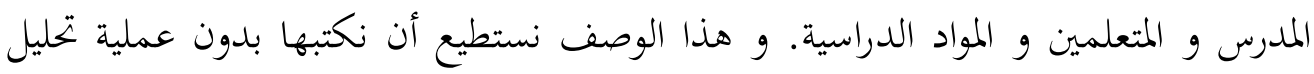
البيانات. و هو لا يخالف الوصف الذي قدمه الصحافي.

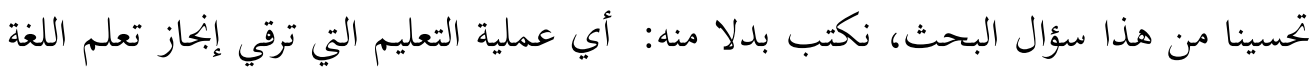

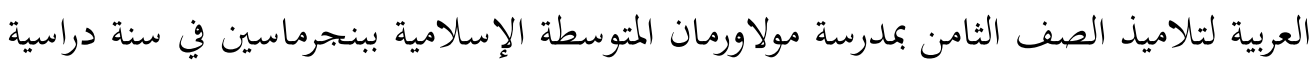

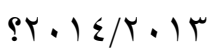

r- أن يتضح في الصياغة وجود متغيرات البحث. أي أن تكون المتغيرات الملاحظة في عملية

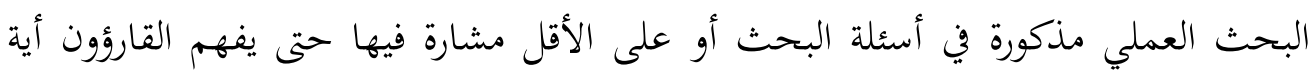
متغيرات مستخدمة في ذلك البحث. المثال: هل تلاميذ الصف الثامن بمدرسة مولاورمان المتوسطة الإسلامية ببنجرماسين الذين

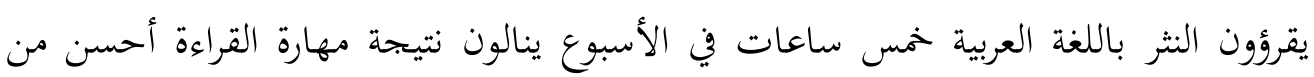

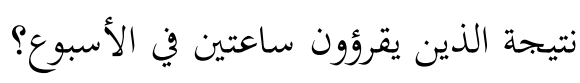
نفهم من هذا سؤال البحث أن المتغير الملاحظ في هذا لئه البحثث اثنان هما تردد قراءة الثثر بالعربية و نتيجة مهارة القراءة.

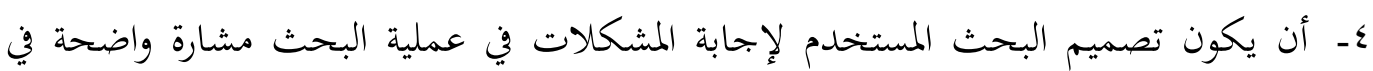

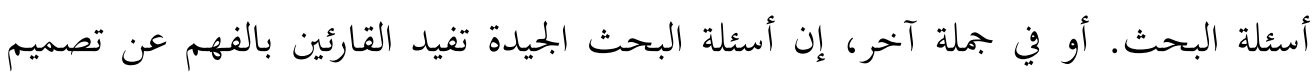

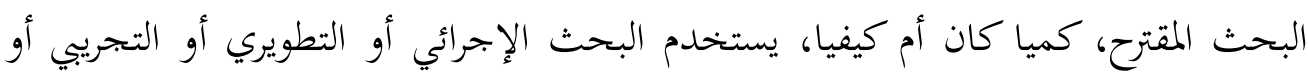

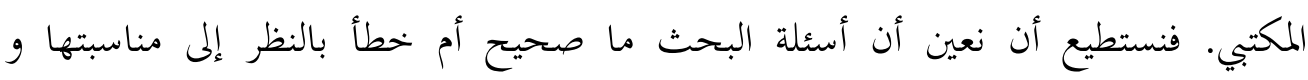
مطابقتها بتصميم البحث المستخدم. المثال ا : أي عملية التعليم التي ترقي إبحاز تعلم اللغة العربية لتلاميذ الصف الثامن بمدرسة

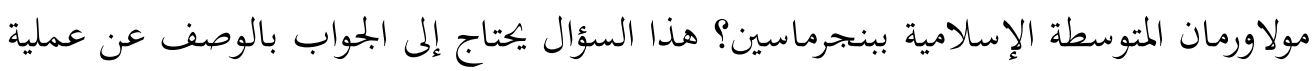
التعليم المعينة و يشير إلى تصميم البحث الوصفي الكيفي.

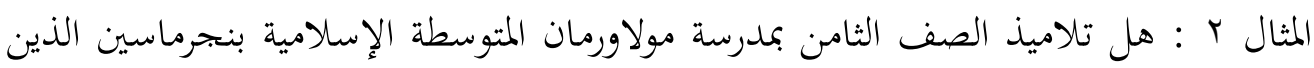

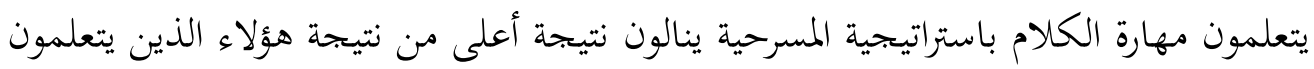

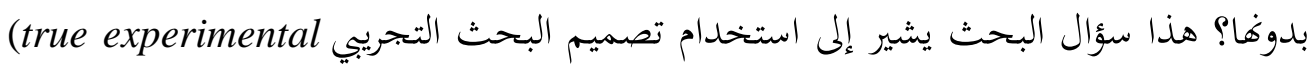

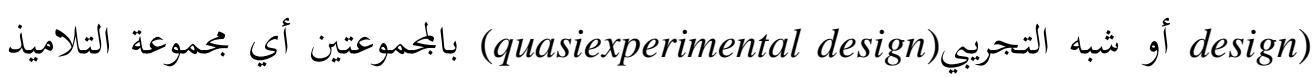

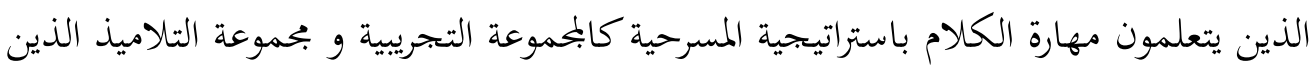
يتعلمون بدوفا كابمموعة الضابطة. 
المثال ץ : هل نتيجة الاختبار البعدي لتلاميذ الصف الثامن بمدرسة مولاورمان المتوسطة الإسلامية بنجرماسين الذين يتعلمون مهارة الكالام باستراتيجية المسرحية أعلى من نتيجتهم في الاختبار القبلي؟ هذا السؤال يشؤر إلى استخدام تصميم البحث التجريبي بمجموعة واحدة (pre-experimental) المثال ؛ : كيف كان تعليم مهارة الكلام باستراتيجية المسرحية لتلاميذ الصف الثامن بمدرسة مولاورمان المتوسطة الإسلامية بنجرماسين؟ و هل استراتيجية المسرحية يستطيع أن يرقي نتيجة مهارة الكلام لتلاميذ الصف الثامن بمدرسة مولاورمان المتوسطة الإسلامية بنجرماسين؟ هذان سؤالان يدل على استخدام تصميم البحث الصفي الإجرائي. المثال ه : ما القيم التربوية المتضمنة في سورة يوسف؟؛ هذا سؤال البحث يشير إلى استخدام تصميم البحث المكتبي. إذا، نفهم من خلال قراءة هذه أسئلة البحث أي طريقة و منهج سيسلكه الباحث في عملية و إجراءات بكثه. ๑- أن تكون أسئلة البحث متعلقة بفرضية البحث المستخدم. 7- أن تكون أسئلة البحث مشيرة إلى حد البحث و نطاقه. لأن حد البحث الواسع سوف يصعب الباحث نفسه في محاولة إجابة بحثه. و هذا الحمد يشمل الزمان و المكان و بحال بحثه.

\section{ي- الخلاصة}

لتكون أسئلة البحث في البحوث العلمية جيدة و مفيدة و سهولة الاستفادة للقارئين فينبغى للباحث في كتابتها الملاحظة فيما يلى: أن تكون أسئلة البحث الجيدة مكتوبة في عبارة واضحة؛ و أن يكون الجواب المراد من أسئلة البحثيتحمل المعلومات عن العلاقات بين الحقائق و الواقعات أو بين المتغيرات الملاحظة أو المعلومات عن الصيغ و الأنماط و انتظام إجراءات العمل الموجودة في موضوع البحث؛ و أن يتضح في الصياغة وجود متغيرات البحث؛ و أن تكون تفيد القارئين بالفهم عن تصميم البحث المقترح؛ أن تكون متعلقة بفرضية البحث المستخدم؛ و أن تكون مشيرة إلى حد البحث و نطاقه. 


\section{المراجع}

ذوقان عبيدات و الآخرون، البحث العلمي مغهومه أدواته أساليبه، (الرياض: دار أسامة)، 199 Vو ربحي مصطفى عليان، البحث العلمي أمسه - مناهجه وأساليبه - إجراء/ته، بيت الأفكار الدولية،

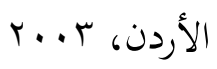

رجاء وحيد دويدري، البحث العلمي؛ أساسياته النظرية و ممارسته العملية، دار الفكر المعاصر،

$$
\text { ب... (بنان }
$$

عبد الرشيد بن عبد العزيز، أساسيات البحث العلمي، (جدة: جامعة الملك عبد العزيز)، سب؟ اهـ

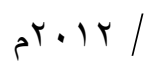

عماد الدين وصفي، البحث العلمي في الإدارة والعلوم الأخرى، دار المعارف الاسكندرية، ب. ب. محمد عثمان الخشت، فن كتابة البحوث العلمية و إعداد الرسائل الجامعية، ابن سينا- القاهرة، 199.

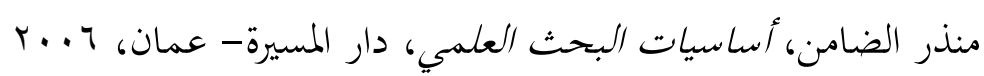

Adnan Latief, Tanya JawabMetodePenelitianPembelajaran Bahasa, (Malang:

UM Press), 2012. 